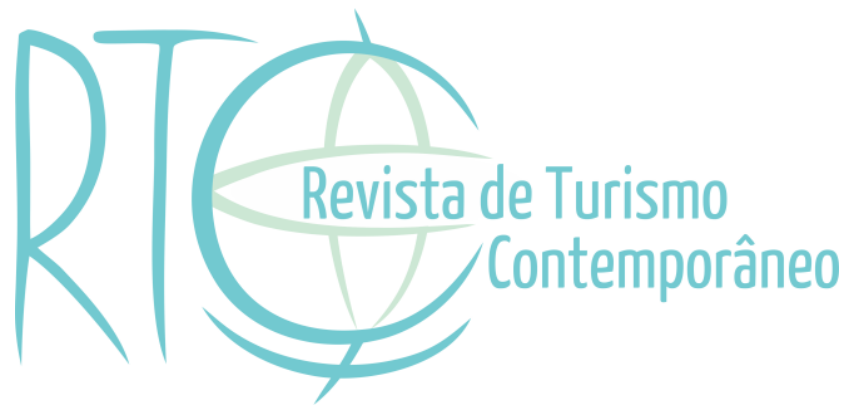

\title{
Turismofobia em Barcelona: um tema (que era?) emergente
}

Tourismphobia in Barcelona: a theme (that was?) emerging

\section{Josefa Laize Soares Oliveira}

Mestranda do Programa de Pós-Graduação em Turismo da Escola de Artes Ciências e Humanidades da Universidade São Paulo - USP, São Paulo/SP, Brasil

E-mail: laizeoliveira@usp.br

\section{Carla Carolina da Silva Neves}

Bacharel em Lazer e Turismo pela Escola de Artes, Ciências e Humanidades da Universidade São Paulo - USP, São Paulo/SP, Brasil

E-mail: carla.carolina.silva@usp.br

\section{Alexandre Panosso Netto}

Professor livre-docente em Teorias do Turismo da Escola de Artes, Ciências e Humanidades da Universidade de São Paulo - USP, São Paulo/SP, Brasil

E-mail: panosso@usp.br

\section{Valéria Ferraz Severini}

Pós-doutoranda do Programa de pós-graduação em Turismo da Escola de Artes, Ciências e Humanidades da Universidade São Paulo - USP, São Paulo/SP, Brasil

E-mail: Valéria Ferraz Severini 


\section{RESUMO}

Os excessos do fenômeno turístico giram em torno de um paradigma social. À medida em que se insere nas dinâmicas que caracterizam uma cidade contemporânea, este campo de atuação e de estudos tornou-se sinônimo de expectativas sobre momentos memoráveis (para quem viaja) e de desenvolvimento socioeconômico (para quem reside em localidades turísticas). Em contrapartida, os efeitos ocasionados pela massificação dos destinos quebram as formas de alcance das projeções positivas, ainda que os interesses entre os atores envolvidos sejam distintos. O objetivo deste artigo foi analisar estes efeitos na rotina de residentes da cidade de Barcelona, na Espanha, bem como aspectos da hostilidade a turistas. Até o final do ano de 2019 e início de 2020, a cidade estava no centro das discussões em torno de um fenômeno denominado turismofobia. Na compreensão de tais questões, foram consultados em profundidade 24 artigos científicos disponíveis na literatura entre turismo, hospitalidade e política. Por meio de análise qualitativa, os resultados revelam que ações para o desenvolvimento do turismo precisam ser repensadas e adaptadas às dinâmicas da turismofobia. Assim, o atual cenário da saúde pública global, em decorrência da pandemia induzida pelo Covid-19, trouxe novas reflexões entre discussões sobre políticas rigidamente sustentáveis e a dinâmica pré-estagnação das viagens.

Palavras-chave: Barcelona. Turismofobia. Turismo de Massa. Gentrificação. Overtourism. Hostilidade.

\section{ABSTRACT}

The excesses of the tourism phenomenon revolve around a social paradigm. As it is inserted into the dynamics that characterize a contemporary city, this field of action and study has become synonymous with expectations about memorable moments (for travelers) and socioeconomic development [for those who reside in tourist locations]. On the other hand, the effects caused by the massification of destinations break the ways of achieving positive projections, even though the interests among the actors involved are distinct. The aim of this article was to analyze these effects on the routine of residents of the city of Barcelona, Spain, as well as aspects of hostility to tourists. By the end of 2019 and early 2020, the city was at the center of discussions around the so-called tourismphobia phenomenon. In understanding such issues, 24 scientific articles available in the literature between tourism, hospitality and politics were consulted in depth. Through qualitative analysis, our results reveal that actions for tourism development need to be rethought and adapted to the dynamics of this phenomenon. Thus, the current global public health scenario, as a result of the pandemic induced by Covid, brought new reflections between discussions on rigidly sustainable policies and the pre-stagnation dynamics of travel.

Keywords: Barcelona. Turismophobia. Mass Tourism. Gentrification. Overtourism. Hostility. 


\section{INTRODUÇÃO}

O fenômeno turístico contemporâneo depara-se com uma realidade que abala os fatores de aproximação entre povos: a massificação. A ação de sair, viajar, conhecer pessoas, lugares, culturas, tornou-se um fenômeno de massa que enfraquece os contatos humanos (Krippendorf, 2002). As discussões entre excessos e sustentabilidade social neste campo são contextos que atribuem significados ao direito de viajar, à liberdade do viajante e aos direitos dos residentes de destinos popularizados (Perkumiené \& Pranskuniené, 2019).

A sensação de que o espaço está sendo invadido e as alterações causadas no modo de vida de residentes de destinos turísticos são um alerta paradoxal para os limites do sucesso da atividade turística. Apesar dos empregos criados e toda a receita gerada pela cadeia produtiva do turismo, residentes de famosos destinos turísticos, tais como as cidades de Veneza (Itália), Londres (Inglaterra) e Santorini (Grécia), já não demonstram tanta alegria e entusiasmo em receber milhões de visitantes. Quando se percebe que os benefícios do turismo são menores que os custos gerados, a intolerância em receber turistas cria o neologismo "turismofobia" - a hostilidade aos visitantes - o que Delgado (2008, s/p [tradução livre]) chamou de "xenofobia substituta" - como de extrema importância nas discussões políticas e institucionais. Tal fenômeno coloca em cheque a hospitalidade e a sustentabilidade econômica, social, cultural e ambiental dos destinos massificados.

As consequências da alta demanda de turistas sobre a economia dos destinos abrem espaço para discussões sobre os efeitos do turismo no ambiente urbano e no bem-estar dos residentes. Alguns autores afirmam que o turismo de massa gera conflitos diretos ou indiretos provocados pelo fluxo de turistas (Swarbrooke, 2000; García, Barrera, \& Scalici, 2019; Postma \& Schmuecker, 2017). Se de um lado a atividade turística garante benefícios positivos e imediatos sobre a economia local (Swarbrooke, 2000; Colomb \& Novy, 2016; García, Barrera, \& Scalici, 2019), de outro lado ela altera significativamente o cotidiano dos moradores levando a um aumento do custo de vida e uma alteração nas dinâmicas sociais existentes.

Segundo Beni (2001), o grupo estável receptor está mesclado pela incorporação de subgrupos de indivíduos provenientes de outras regiões e de outras culturas. Isso causa grandes mudanças na estrutura da população que originalmente viviam no local. Assim, para impedir o avanço dos efeitos negativos, reflexões articuladas mostram-se como ferramentas que visam promover um equilíbrio (Milano, 2018; Milano, Novelli, \& Cheer, 2019). Este pensamento está na direção de que, embora o turismo tenha se convertido tanto em um ciclo de reconstituição das necessidades do homem [o cotidiano x o anti-cotidiano], bem como na produção e 
reprodução do capital (Krippendorf, 2002; Milano, 2018; Milano, Novelli, \& Cheer, 2019), não se pode ignorar os problemas sociais vinculados às atividades que o compõe.

Neste contexto, o principal objetivo deste artigo é analisar os efeitos do turismo massivo na rotina de residentes, bem como os efeitos da hostilidade aos turistas, ponto de referência a cidade de Barcelona, na Espanha. A cidade é conhecida como exemplo típico sobre o tema da superlotação nos destinos e uma espécie de laboratório para implementar medidas pioneiras quanto a políticas públicas e estratégias inovadoras de gestão. Trata-se de uma análise sobre a parcela do turismo no processo de gentrificação - que, entre outros aspectos, modifica a identidade de bairros tradicionais e dispara preços imobiliários -, a influência midiática em relação à projeção da fobia no turismo, além da importância de abordagem sobre um turismo sustentável em seus vários aspectos.

Este artigo está estruturado em três divisões: i) revisão da literatura, abordando as questões centrais do turismo em Barcelona; ii) descrição da metodologia utilizada e; iii) discussão sobre como o turismo de massa influencia o processo de gentrificação na cidade e de que forma esse processo afeta a hospitalidade do lugar. Os resultados evidenciam que ações para o desenvolvimento do turismo precisam ser repensadas e adaptadas às dinâmicas deste fenômeno. Pensando em longo prazo, sem alternativas socialmente sustentáveis, pode-se cogitar que o setor do turismo caminha rumo a um ponto no qual mudanças profundas serão, ou já são, necessárias e eminentes.

É importante registrar que este texto começou a ser redigido em fins de 2019, antes do surgimento da pandemia do Covid-19 e quando não havia estagnação das viagens no mundo. Desde o início a proposta era apresentar ao XVII Seminário da ANPTUR em 2020, por isso, a ideia foi mantida até o momento. Considerando estes aspectos, nas reflexões finais este contexto é apresentado, ainda que de forma breve.

\section{REVISÃO DE LITERATURA}

O processo de desindustrialização das grandes cidades, em especial no final do século passado, transformou o turismo em importante fenômeno de renovação urbana. Para além da trivial "indústria sem chaminés", o interesse em vender cidades como produto turístico garantiu ganho e acúmulo de capital para o funcionamento do sistema capitalista (Milano, 2018; Milano, Novelli, \& Cheer, 2019). Com isso, antigas cidades industriais que não se adaptaram a este novo processo sofreram declínio econômico (Swarbrooke, 2000).

Em diversas regiões do mundo diferentes abordagens estratégias foram articuladas para alavancar a economia de cidades em quadro de declínio econômico (Swarbrooke, 2000). Na 
Europa, por exemplo, no final da década de 1980 o programa Capital Europeia da Cultura, de 1999, instituído pela União Europeia, surgiu como estratégia para a promoção do turismo histórico e cultural em cidades pouco visadas pelo mercado global de turismo. A Espanha se destacou nessa estratégia. Tal ação ajudou a alavancar o reconhecimento internacional de cidades como Madrid (Swarbrooke, 2000), no mesmo ano em que aconteceram os Jogos Olímpicos de Barcelona, em 1992, e a Expo 92 em Sevilha.

No período de destaque turístico da Espanha, Barcelona passou por um projeto de reforma e condicionamento urbano. Os mega eventos foram catalisadores de aspirações turísticas, e as projeções positivas do destino a nível mundial refletiram em crescimento contínuo da oferta e demanda num curto espaço de tempo (Alcalde, Guitart, Pitarch, \& Vallvé, 2018; Ballester, 2018). Pesados investimentos foram realizados no país no final do século XX e início do XXI, entre eles: a reforma do Aeroporto Madrid-Barajas (o quarto maior da Europa), a implantação do VLT (Veículo Leve Sobre Trilhos) e quatro novas linhas de metrô em Barcelona, a construção do Museu Guggenheim em Bilbao e a implantação do Madrid Río Park junto ao Rio Manzanares em Madrid.

O sucesso do turismo e o aumento da oferta hoteleira da Espanha antecede a um fenômeno de massas. A partir do controverso paradoxal entre recuperar cidades em declínio econômico, o chamado boom turístico (entre 1950 e 1970) e a evolução de modais de transporte aéreo no início do século $\mathrm{XX}$ - fatores que tornaram as viagens mais acessíveis -, passou-se a questionar os limites de ações municipais (Ballester, 2018; Milano, 2018). No caso de Barcelona, ao tornar-se destaque mundial de notícias relacionadas à alta demanda de visitantes, a cidade ficou conhecida como berço do que supostamente seria uma fobia ao turismo. Assim surgiu o termo "turismofobia", abordado como uma aversão aos turistas e reconhecido como um neologismo válido na Espanha desde 2017 (Fundación del Español Urgente - Fundéu, 2017; Huete \& Mantecón, 2018; Quaglieri, 2018). 


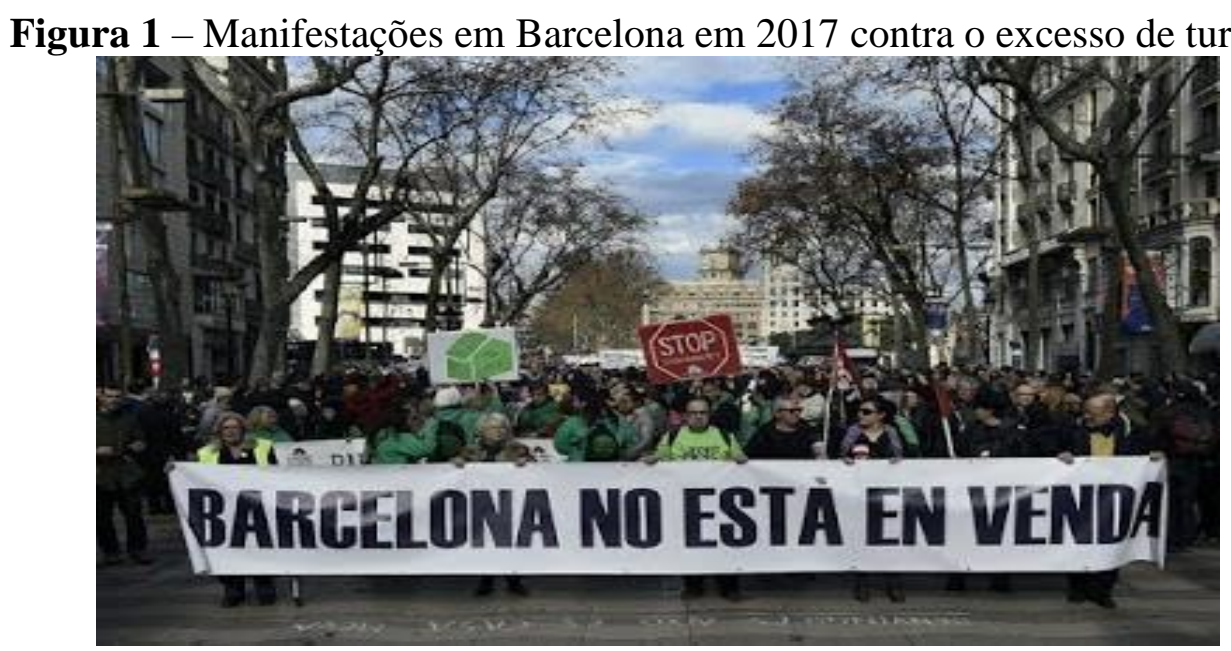

Fonte: Notícia publicada no site Walthealvarenga.com, 2017.

Capital cosmopolita da comunidade autônoma de Catalunha, Barcelona possui uma população de 1.620.343 habitantes, segundo dados do Instituto Nacional de Estadística - INE ${ }^{1}$ de 2018. O informe Observatori del Turisme a Barcelona: ciutat i regió (2019) trouxe dados importantes para a reflexão sobre os excessos do turismo na capital. Em 2019, Barcelona recebeu 9.472.562 de turistas, um crescimento de 3,9\% em comparação ao ano de 2018. Ao considerar a área urbana de 101,9 km² (Ajuntament de Barcelona, 2006), evidencia-se que a somatória da demanda de turistas (2019) e o número de habitantes da cidade (2018) equivalem ao número de 10,8 pessoas por $\mathrm{m}^{2}$.

À luz dos debates sobre o que alguns estudiosos chamam de decrescimento do turismo (Milano, Novelli, \& Cheer, 2019) o paradigma de desenvolvimento onde se insere o campo já foi questionado desde teorias sociais das décadas de 1970 e 1980 (Doxey, 1975; Butler, 1980; O’Reilly, 1986; Postma \& Schmuecker, 2017; Milano, 2018). Dentre as teorias que apontam para os limites de crescimento do turismo e suas consequências, destacam-se o Índice de Irritabilidade Turística, que explica graus de irritabilidade entre turistas e residentes de acordo com estágios o desenvolvimento turístico dos destinos (Doxey, 1975); o Ciclo de Vida Turístico, que explica a fase de evolução da demanda de turistas até a capacidade limite das destinações (Butler, 1980) e a Capacidade de Carga Turística, que reflete sobre os limites máximos desta demanda por área (O’Reilly, 1986).

$\mathrm{Na}$ atualidade, novas perspectivas de planejamento sustentável surgem todos os anos por meio das contribuições dos campos de investigação acadêmica. Postma e Schmuecker (2017) e Arias-Sans e Milano (2019), por meio de um modelo conceitual e de acordo com cada

\footnotetext{
${ }^{1}$ Recuperado de https://www.ine.es/
} 
contexto, identificaram as esferas de conflito de acordo com a realidade de cada destino. Em linhas gerais, a gerência do fluxo de turistas, alterações estruturais ao paradigma econômico que centraliza o turismo contemporâneo, além de regulamentação mais rígida e novas reflexões em torno da relação homem-ambiente, têm sido vistos como modelos alternativos às soluções (Postma \& Schmuecker, 2017; Milano, 2018; González, 2018; Milano, 2018; Hall, 2019). Dentro da agenda das políticas urbanas, discute-se como ferramenta estratégica de contenção da superlotação turística o implemento dos 5D's (dessazonalização; descongestionamento; descentralização; diversificação; e turismo de luxo) na gestão dos destinos (Milano, 2018; Milano, Novelli, \& Cheer, 2019). Contudo, apesar das medidas e preocupações direcionadas à sustentabilidade, no que diz respeito à utilização de recursos, o turismo tem sido mais insustentável do que nunca (Hall, 2019).

Por esses aspectos, a atividade turística massificada em Barcelona leva a uma visão pessimista. Observa-se que entre a imagem positiva gerada pelo crescimento do turismo ao caos impulsionado pelo sucesso excessivo, despontou uma contradição sobre a dinâmica que tornou o destino visado. Ao refletir sobre o ciclo de vida de um destino turístico, baseado no modelo de Butler (1980), percebe-se que os resultados da superlotação na infraestrutura de Barcelona comprometem seu potencial turístico. A saturação da capital trouxe ao centro dos debates um antagonismo de faces. A divergência de interesses entre turistas e residentes sugere que os impactos gerados pelo turismo massivo precisam de atenção nas duas pontas do conflito.

Na perspectiva de análise da turismofobia como um fenômeno recente, a estratégia de busca dos dados caracterizou-se como exploratória-descritiva (Triviños, 2008). Para a análise dos dados obtidos este estudo possui caráter qualitativo (Marconi \& Lakatos, 2002) e utilizou como técnica a revisão bibliográfica, com levantamento de informações disponíveis em livros, sites, artigos acadêmicos, e dissertações em diferentes bases de dados na web. Assim foi elaborado o Quadro 01 com as principais referências encontradas. Estas referências discutem a superlotação turística em Barcelona e como a divergência de interesses entre turistas e residentes tornou-se o ponto central nos debates políticos e institucionais sobre os excessos do turismo no destino. 


\begin{tabular}{|c|c|c|c|c|c|c|}
\hline Autores & Abordagem & $\begin{array}{l}\text { Perspectiva } \\
\text { teórica }\end{array}$ & Área & Revista & País & Ano \\
\hline Alcalde et al. & Quali. & $\begin{array}{l}\text { Convivência } \\
\text { turística }\end{array}$ & Turismo & ARA & Espanha & 2018 \\
\hline Almeida et al. & Quali. & $\begin{array}{c}\text { Mídia Social e } \\
\text { Turismo }\end{array}$ & Turismo & $\begin{array}{l}\text { Sustainability } \\
\text { Magazine }\end{array}$ & Espanha & 2019 \\
\hline $\begin{array}{l}\text { Almeida-Gar } \\
\text { cía et al. }\end{array}$ & Quali. & $\begin{array}{l}\text { Atitudes dos } \\
\text { residentes e } \\
\text { impactos do } \\
\text { turismo }\end{array}$ & Turismo & $\begin{array}{c}\text { Tourism } \\
\text { Management } \\
\text { Perspectives }\end{array}$ & Espanha & 2015 \\
\hline $\begin{array}{l}\text { Arias-Sans \& } \\
\quad \text { Milano }\end{array}$ & Quali. & Turismo urbano & Turismo & Overtourism & Espanha & 2019 \\
\hline $\begin{array}{l}\text { Almeida-Gar } \\
\text { cía et al. }\end{array}$ & Quanti. & $\begin{array}{c}\text { Turismofobia em } \\
\text { Málaga }\end{array}$ & Turismo & $\begin{array}{l}\text { Boletín de la } \\
\text { Asociación de } \\
\text { Geógrafos } \\
\text { Españole }\end{array}$ & Espanha & 2019 \\
\hline Ballester & Quali. & $\begin{array}{l}\text { Barcelona e o } \\
\text { turismo de massa }\end{array}$ & Turismo & Téoros & França & 2018 \\
\hline Campos & Quali. & $\begin{array}{l}\text { Gentrificação } \\
\text { nas cidades }\end{array}$ & Turismo & $\begin{array}{l}\text { Revista } \\
\text { Percursos }\end{array}$ & Brasil & 2008 \\
\hline Colau & Quali. & $\begin{array}{l}\text { Turismo de } \\
\text { Massa }\end{array}$ & Turismo & The Guardian & Espanha & 2014 \\
\hline Colau & Quali. & $\begin{array}{c}\text { Xenofobia em } \\
\text { Barcelona }\end{array}$ & Política & The Guardian & Espanha & 2020 \\
\hline Donaire & Quali. & $\begin{array}{l}\text { Crescimento do } \\
\text { turismo e a } \\
\text { sociedade }\end{array}$ & Turismo & $\begin{array}{c}\text { Barcelona } \\
\text { Metropolis: } \\
\text { Revista } \\
\text { d'informació i } \\
\text { pensament } \\
\text { urbans }\end{array}$ & Espanha & 2008 \\
\hline Ferraz & Quali. & $\begin{array}{l}\text { Hospitalidade } \\
\text { urbana em } \\
\text { grandes cidades }\end{array}$ & Hospitalidade & & Brasil & 2013 \\
\hline $\begin{array}{c}\text { García } \\
\text { Bujalance }\end{array}$ & & $\begin{array}{l}\text { Economia nas } \\
\text { cidades e o } \\
\text { turismo }\end{array}$ & Turismo & $\begin{array}{c}\text { Revista de } \\
\text { Turismo } \\
\text { Contemporâneo }\end{array}$ & Espanha & 2019 \\
\hline Gonzalez & Quali. & $\begin{array}{l}\text { Overtourism e os } \\
\text { impactos em } \\
\text { cruzeiros }\end{array}$ & Turismo & $\begin{array}{c}\text { Journal of } \\
\text { Regional } \\
\text { Research }\end{array}$ & Espanha & 2018 \\
\hline Hall & Quali. & $\begin{array}{l}\text { Desenvolviment } \\
\text { o sustentável do } \\
\text { turismo }\end{array}$ & Turismo & $\begin{array}{c}\text { Journal of } \\
\text { Sustainable } \\
\text { Tourism }\end{array}$ & $\begin{array}{c}\text { Nova } \\
\text { Zelândia }\end{array}$ & 2019 \\
\hline $\begin{array}{l}\text { Huete e } \\
\text { Mantecón }\end{array}$ & Quali. & $\begin{array}{l}\text { Auge da } \\
\text { turismofobia }\end{array}$ & Turismo & $\begin{array}{c}\text { Revista de } \\
\text { Turismo y } \\
\text { Patrimonio } \\
\text { Cultural }\end{array}$ & Espanha & 2018 \\
\hline
\end{tabular}

Fonte: Elaborado pelos autores, 2020. 
O Quadro 1 apresenta 24 artigos que abordam o tema em questão. Destaca-se a variedade de autores e a variedade de revistas nas quais foram publicadas, porém com grande concentração na Espanha, como era de se esperar. Além disso, são artigos publicados entre os anos 2014 e 2019, evidenciando a crescente importância recente que o tema adquiriu naquele período histórico.

\section{ANÁLISE E DISCUSSÃO}

Críticas aos excessos do turismo foram rotuladas como turismofobia, porém a maioria dos autores destaca que o termo foi manipulado e popularizado por meio da mídia (tal como fazem Quaglieri, 2018; Huete \& Mantecón, 2018). Diante da falta de homogeneidade quanto sua definição, aponta-se para a necessidade de substituí-lo por conceitos que atribuem devidos significados (Alcalde et al., 2018).

Alguns autores usam o termo overtourism como mais adequado ao tema da superlotação nos destinos (Almeida et al., 2019; Milano et al., 2019; Perkimiené \& Pranskuniené, 2019; González, 2018) pois o neologismo turismofobia é identificado como uma crítica ao modelo de turismo de massa, e não uma rejeição aos turistas ou ao turismo como sugere a denotação (Quadro 2).As respostas eram digitadas ao final de cada entrevista em tablet pela própria pesquisadora e posteriormente foram ineridos no programa Microsoft Office Excel 2010.

\begin{tabular}{|c|c|c|}
\hline Autores & Ano & Conceituação de turismofobia \\
\hline Delgado & 2008 & $\begin{array}{c}\text { "Uma mistura de repúdio, desconfiança e desprezo por esta figura que todos já } \\
\text { designam com a denominação de origem Guiri" (Delgado, 2008, S/P [tradução } \\
\text { livre]). }\end{array}$ \\
\hline $\begin{array}{c}\text { Alcalde et } \\
\text { al. }\end{array}$ & 2018 & $\begin{array}{l}\text { "O conceito de turismofobia tem sido usado lamentável e inadequadamente, } \\
\text { confundindo a agitação social devido ao excesso de turismo [...] para a rejeição } \\
\text { de } \\
\text { turistas como indivíduos" (Alcalde et al., 2018, p. } 27 \text { [tradução livre]). }\end{array}$ \\
\hline Milano & 2018 & $\begin{array}{l}\text { [...] "O eco atual das ações de protesto, em Barcelona e em outras cidades do } \\
\text { Estado } \\
\begin{array}{c}\text { espanhol, foi reduzida a instrumentalização política e ao sensacionalismo da } \\
\text { mídia }\end{array} \\
\text { sobre o apelido de turismo/turismofobia", (Milano, 2018, p. } 556 \text { [tradução } \\
\text { livre]). }\end{array}$ \\
\hline
\end{tabular}


Almeida-

García

et al.
2019

$$
\begin{array}{r}
\text { “Em geral, não há rejeição de turistas, ma } \\
\text { impactos }
\end{array}
$$

[...] o que é chamado turismofobia parece ser uma crítica ao modelo de gestão de

turismo"'(Almeida-Garcia et al., 2019, p. 26 [tradução livre]).

Fonte: Elaborado pelos autores, 2020.

Legitimados pelo sensacionalismo midiático, os debates sobre os excessos do turismo em Barcelona foram atribuídos à opinião pública e a instrumentalização política (Milano, 2018). Contudo, os relatos de protestos de residentes nos diferentes meios de comunicação contribuíram para ofuscar os conflitos reais a favor dos interesses próprios dos atores da mídia (Postma \& Schmuecker, 2017). O deturpar em torno das projeções do fenômeno da superlotação nos destinos ofuscou também a realidade e o relacionou a algo tão extremo quanto a xenofobia (Alcalde et al., 2018), tal como dito por Delgado (2008, s/p [tradução livre]) uma estrutura idêntica ao "racismo vulgar" que se aplica ao imigrante.

Para Beni (2020), o mal estar social em relação à saturação em Barcelona foi "patologizado" por meio do uso impreciso de um termo atribuído à rejeição. Quaglieri (2018), analisa que, frente à complexidade de práticas e posturas relacionadas ao turismo o sufixo "fobia" reflete uma carga negativa injustificável ao turismo. Logo, percebe-se um paradoxo na atribuição de um conceito relativo a medo em um grau de superioridade à realidade. Embora o termo reflita as consequências negativas atribuídas à atividade turística, e sua definição etimológica associa-se a uma perturbação fóbica, o neologismo "turismofobia" é rejeitado pela maioria dos residentes em Barcelona (Alcalde et al., 2018).

Relativo às projeções midiáticas, evidenciou-se uma luta ideológica entre estruturas discursivas que não se articulam, mas que intencionam resolver a situação (Huete \& Mantecón, 2018). Os discursos refletem em atitudes provenientes principalmente de movimentos sociais organizados que se mobilizam contra o modelo de turismo contemporâneo, sublinhado pela agenda política de interesse particular (Milano, Novelli, \& Cheer, 2019). Huete e Mantecón (2018) identificaram por meio de análise de diferentes notícias relacionadas ao tema que o turismo passou a fazer parte de discursos com linhas de ação que vão desde a subversão ao capitalismo a confrontações e reivindicações políticas.

Apesar da complexidade da abordagem sobre a mudança de paradigma de crescimento para decrescimento do turismo (Milano, Novelli, \& Cheer, 2019), Ballester (2018) analisa que os sinais de incômodo manifestados mostram as formas de pensar sobre a cidade, e de possíveis 
acordos de conciliação entre residentes e turistas que podem inibir o avançar de crises de revolta urbana em toda a cidade e região da Catalunha, pois a pressão turística está principalmente em uma parte do centro de Barcelona.

\subsection{Os residentes frente aos impactos do turismo: a gentrificação}

As evidências dos efeitos negativos gerados pela superlotação em Barcelona mostram que os debates em torno do assunto assumiram novas formas com o passar dos anos. AriasSans e Milano (2019) observam que enquanto antigas discussões tinham foco no comportamento dos turistas, os novos debates associam-se às questões urbanas que afetam o cotidiano dos residentes. A filosofia destas discussões parte de reflexões fragmentadas em discursos de grupos distintos de residentes: o "turismofóbico" (pessoa de meia idade) que preocupa-se com as consequências que afetam a vida cotidiana, e o "turismofílico" (população tradicional) que preocupa-se com os processos da gentrificação (Almeida-García, CortésMacías, \& Balbuena Vázquez, 2019).

A palavra gentrificação é uma tradução do inglês (gentrification) e está associada à ideia de "origem nobre, pessoas bem nascidas e de classe social alta". O aumento da demanda por imóveis, impulsionado pela atividade turística, estimula o aumento no preço dos aluguéis e no custo de vida da região. Esse processo gera uma expulsão natural da população moradora, gentrificando o local que passa a ser frequentado apenas por turistas ou por pessoas com poder aquisitivo mais alto (Ribeiro, 2014). Ao longo do tempo, o lugar passa a ter uma diversidade menor de pessoas e de tipos de estabelecimentos comerciais e de serviços que passam a atender apenas a uma população flutuante (turistas). Esse processo pode fazer com que o lugar se torne “artificial” e, em alguns casos, passe a sensação de lugar inseguro.

Para Swarbrooke (2000), administrar a pressão do rápido crescimento da demanda de turistas em cidades históricas é um desafio da atualidade. Destaca-se que este autor já fez esta observação há mais de 20 anos. Alguns autores afirmam que a ascensão do turismo de massa em uma cidade histórica impulsiona conflitos gerados pelo processo de gentrificação (García, Barrera, \& Scalici, 2019). Sobre tais transformações, Alcalde et al. (2018, p. 27 [tradução livre]) analisam que "a busca por benefícios de curto prazo contribui para perder de vista as consequências geradas sobre a dinâmica da cidade". Tal fenômeno promove a remodelação de espaços urbanos, modificando localidades e tornando espaços segregados.

Neste sentido, o turismo torna-se excludente e prejudicial ao bem-estar dos residentes, pois a gentrificação: 
[...] implica um conjunto de processos específicos que alteram a ocupação de áreas urbanas utilizadas por camadas populares. Ela implica uma série de transformações relacionadas à moradia, ao mercado imobiliário, à circulação de pessoas, e às formas de sentir (e perceber) as cidades (Campos, 2008, p. 100).

As dinâmicas da gentrificação como um fenômeno econômico relacionado à turistificação estão causando uma série de efeitos que impulsionam o mal-estar social. A perda de patrimônio histórico para dar lugar a hotéis, por exemplo, resulta na perda de identidade e das raízes dos residentes (García, Barrera, \& Scalici, 2019). Em Barcelona, segundo Ballester (2018), a vida na vizinhança está morrendo e aos poucos os moradores não reconhecerão a cidade em que residem, como mostra o documentário Bye Bye Barcelona de Eduardo Chibás (2014).

De outro modo, a gentrificação contribui para que o processo de desigualdade social seja acentuado por meio da reestruturação urbana, afetando principalmente as camadas sociais que não possuem imóveis (Vives-Miró \& Rullan, 2017). O novo cenário social desenha o que os estudiosos analisam como uma reconfiguração da paisagem, um ambiente moldado (VivesMiró \& Rullan, 2017; Mansilla, 2018), "uma cidade palco" como argumentou Donaire (2008, s/p [tradução livre]). Barcelona teria projetado um cenário que foge da identidade sui generis.

Mansilla (2018) analisa o papel dos movimentos sociais como um impedimento a essas novas formas de exclusão que provocam o deslocamento dos vizinhos com menor poder aquisitivo. Nesta linha, García, Barrera e Scalici (2019) observam que para evitar as transformações de lugares que expulsam antigos moradores para dar espaço aos turistas é necessário agir sobre os conflitos entre ambos, e que o alcance de equilíbrio entre as atividades que compõem o turismo e o uso do solo urbano só será possível caso os residentes recebem voz sobre o assunto.

Huete e Mantecón (2018), por sua vez, descrevem que em Barcelona os residentes não são ouvidos tanto quanto deveriam. Por conseguinte, os turistas são vistos como fator de "poluição e perigo", uma “irrupção anómala a combater" que generaliza o fenômeno de rejeição frontal (Delgado, 2008, s/p).

\subsection{Os turistas frente à hostilidade}

No contexto dos efeitos do turismo de massa, a opinião pública passa a tomar consciência sobre as consequências para o tecido urbano e social (Ballester, 2018). Contudo, percebe-se que os direitos dos viajantes recebem maior proteção (Perkumiené \& Pranskumiené, 2019) e em meio a esta conjuntura, nas posições discursivas, os residentes receberam pouca voz para o tratamento desta abordagem (Huete \& Mantecón, 2018). 
Na tentativa de expressar as insatisfações provindas da massificação turística na capital catalã, os barceloneses revelaram as faces da insatisfação em manifestações de menor à maior escala, caracterizando uma imagem sistêmica da tentativa de afastar turistas.

Nas insatisfações manifestadas evidenciou-se um mal-estar perante a sensação de invasão de seu espaço público (Ballester, 2018). Entre cartazes e pichações, frases como "Barcelona no está en venda", ou "El turismo mata los barrios", demonstram a indignação de quem perdeu o direito de viver a cidade na qual reside - direito este já questionado há quase cinco décadas por Lefebvre (1974) em sua obra originalmente intitulada Le Droit à la Ville. De outro modo, expressões como "Tourist go home", ou "All tourists are bastards", sugerem que os turistas não são bem-vindos e criam uma atmosfera hostil.

Figura 2 - All tourists are bastards, Barcelona

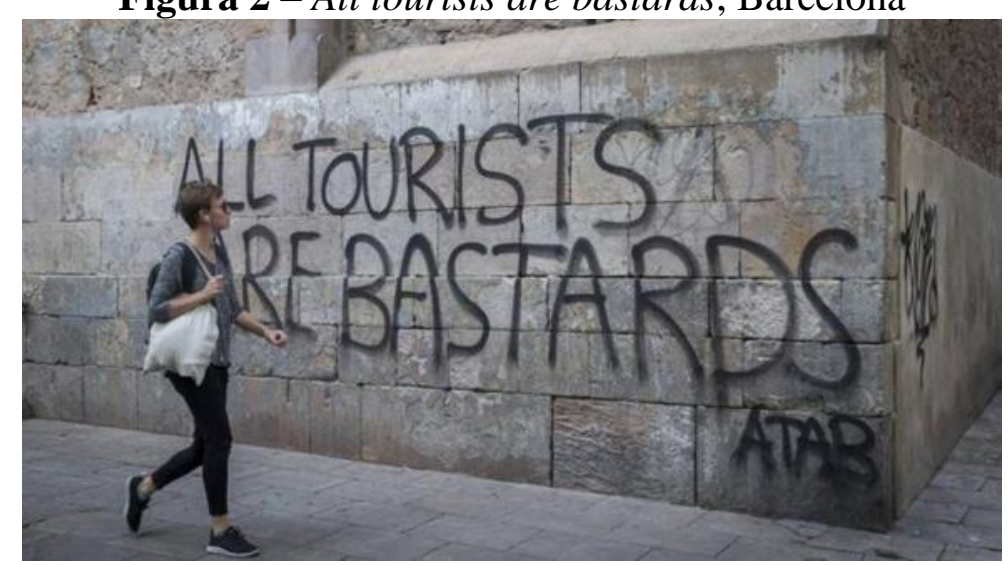

Fonte: Notícia publicada no site do Jornal El País (Oliveira, 2017).

Dentre manifestações de cunho severo, atentados terroristas foram atribuídos a grupos extremistas anti-turismo. Em 17 de agosto de 2017, no pico das visitas à cidade de Barcelona, uma pessoa dirigindo uma van atropelou vários pedestres em La Rambla - um dos locais turísticos mais visitados da cidade. Segundo o jornal Internacional El País, 100 pessoas ficaram feridas e 14 morreram devido ao ataque (Oliveira, 2017).

Diante dos ataques terroristas e manifestações de cunho mais leve, a Organização Mundial de Turismo (OMT), demonstrou preocupação com a crescente intolerância com turistas e pediu que os governos trabalhassem para que o setor se desenvolva de modo sustentável, assegurando que o turismo seja uma experiência enriquecedora, tanto para visitantes quanto para moradores. Isso reforça a ideia de hospitalidade urbana, que é o ato de recepcionar, hospedar, alimentar e entreter pessoas (turistas ou moradores) no meio urbano, de forma a garantir uma somatória de sensações de bem-estar e de acolhimento (Ferraz, 2013). 
No âmbito da política, opiniões subjetivas e públicas fazem emergir reflexões ainda mais complexas em torno dos simbolismos da questão. $\mathrm{O}$ artigo de Ada Colau (atual prefeita de Barcelona em 2021) para o jornal The Guardian (Colau, 2014) trouxe um título tendencioso: “Mass tourism can kill a city - just ask Barcelona's residentes". Em contrapartida, nas palavras ativistas por melhorias no modo de vida dos barceloneses, a autora destacou a importância da regulamentação do setor, em oposição a manifestações contra o turismo ou a turistas. Seis anos após a publicação, Colau (2020) escreveu sobre a luta das cidades europeias contra a xenofobia, em críticas à violação dos direitos humanos.

Neste contexto, o atual cenário da saúde pública global, em decorrência da pandemia induzida pelo Covid-19, trouxe novas reflexões sobre a massificação do turismo em Barcelona. Neste pensamento, apesar de não ser foco deste artigo, o que acontece em Barcelona pode ser semelhante ao que está acontecendo em outras capitais mundiais do turismo, tal como Veneza, "que antes asfixiada por los turistas, Venecia ahora agoniza por su ausencia $2 "$. Ou seja, os destinos encontram-se numa posição complexa de vários caminhos a seguir: deixar como está e continuar o desenrolar do processo turístico sem interferências; intervir para diminuir os fluxos turísticos e assim sacrificar o aporte financeiro que o turismo gera no local; sobrecarregar os residentes locais com o mesmo modelo turístico; impor limites mais duros para as empresas do setor turístico, etc. Qualquer que seja a posição tomada será conflituosa frente às inúmeras visões e dinâmicas possíveis do fenômeno turístico.

\section{CONSIDERAÇÕES FINAIS}

Este artigo buscou analisar os efeitos negativos do turismo massivo na rotina de residentes, e os efeitos da hostilidade aos turistas, tendo como estudo de caso a cidade de Barcelona. Foram evidenciadas as consequências que a atividade turística pode desencadear, em especial no território urbano e nas relações sociais. A reação dos moradores diante do excesso de turistas na cidade de Barcelona alerta para a necessidade urgente de se pensar um novo modelo de turismo, socialmente mais participativo e sustentável em seus múltiplos aspectos, que leve em consideração os desejos e anseios de sua população local.

Em primeiro plano, a análise qualitativa dos resultados revela que existem confusões quanto à interpretação das mudanças sociais provocadas pelo turismo na cidade frente às manifestações dos residentes. Desde 2014, quando aflora o tema da massificação do turismo

\footnotetext{
${ }^{2}$ Recuperado de https://www.lanacion.com.ar/el-mundo/antes-asfixiada-por-los-turistas-venecia-aho ra-agonizapor-su-ausencia-nid2363522
} 
em Barcelona, surgem termos que buscam explicar essa mudanças, tais como overtourism e turismofobia. Ao que tudo indica, este último, apesar de receber críticas dos estudiosos (como evidenciado neste artigo), é o que ganhou maior notoriedade, ao menos nesta localidade e, por vezes, propõe os residentes como fóbicos ao turismo, o que não foi evidenciado. Ao contrário, percebeu-se forte crítica ao turismo em sua face capitalista: o excesso da demanda de turistas, visando apenas benefícios econômicos que concentram o capital.

Ademais, analisar o "modelo de sucesso de turismo" da Espanha, em alguma medida, pode ser exemplo para o Brasil, que há anos não consegue sair da marca de 6 (seis) milhões de turistas internacionais por ano. Se, de um lado o turismo espanhol mostra o quanto é importante investir pesado em infraestrutura urbana (aeroportos, estações de trem e metrô, construção de grandes museus e projetos ousados de revitalização urbana) não só para atrair turistas, mas para melhorar a qualidade de vida da população, de outro ele alerta para a necessidade de elaborar programas e políticas públicas que assegurem que a atividade turística não privilegie apenas os empresários do setor.

Os resultados também revelam que ações para o desenvolvimento do turismo precisam ser repensadas e adaptadas às dinâmicas deste fenômeno. Por exemplo, a encruzilhada que o overtourism, a turismofobia e a pandemia de Covid-19 colocam não só Barcelona, mas também outras "Mecas" do turismo mundial. Seria este o momento de intervir na já estagnada economia do turismo mundial para revisar os modelos de gestão de turismo? Ou seria este o momento de aproveitar ao máximo os benefícios econômicos da atividade para reerguer o setor, mesmo que isso estresse mais os residentes das localidades já massificadas? O ponto de equilíbrio desta equação não é fácil de ser encontrado, se é que existe.

Entre discussões sobre a renovação do setor (políticas rigidamente sustentáveis), e a retomada do turismo (em sua dinâmica pré-estagnação), percebe-se a urgência das análises em torno de tais questões. A retomada da atividade turística representa, dentre muitos aspectos, o impulsionar de setores econômicos abalados pela pandemia. Em contrapartida, os novos fenômenos que surgem, como a fadiga de quarentena ${ }^{3}$, podem induzir uma retomada brusca da demanda e o planejamento não sustentável repercutiria em novos fenômenos em torno da massificação do destino.

Como limitações, este estudo reflete que os acadêmicos que se debruçaram sobre o tema buscaram oferecer análises sobre a situação de Barcelona, mas nem sempre são unânimes em

\footnotetext{
${ }^{3}$ Recuperado de https://jornal.usp.br/atualidades/fadiga-da-quarentena-mecanismo-psicologico-incentiva-oabandono-do-confinamento/
} 
suas posições, uma vez que se trata de tema complexo e, significativamente, novo. Pode-se inclusive afirmar que não há um caminho só a ser seguido ou que as possibilidades de atuação e encaminhamentos são amplos. Na prática, caberia aos gestores locais - e stakeholders de todo o setor turístico do município - definir os caminhos a serem seguidos. Contudo, ressalta-se que tais caminhos estão ainda mais obscurecidos pela pandemia de Covid-19.

\section{REFERÊNCIAS}

Ajuntament de Barcelona. (2006). Informações gerais sobre Barcelona. Recuperado em 29, fevereiro, 2020, de https://www.barcelona.cat/es/

Alcalde, J., Guitart, N., Pitarchr, A., \& Vallvé, O. (2018). De la turismofobia a la convivencia turística: el caso de barcelona. Revista de Investigación en Turismo, Barcelona, Espanha, (2) 25-34.

Almeida-García, F., Balbuena-Vázquez, A., \& Cortés-Macías, R. (2019). Tourismphobia in historic centres: the case of Malaga. Boletín de la Asociación de Geógrafos Españoles, 1-32.

Arias-Sans, A., \& Milano, C. (2019). Case study 3: Barcelona, Spain. World Tourism Organization, Centre of Expertise Leisure, Tourism \&amp; Hospitality. NHTV Breda University of Applied Sciences, and NHL Stenden University of Applied Sciences. Madrid: UNWTO.

Ballester, P. (2018). Barcelone face au tourisme de masse: tourismophobie et vivre ensemble. Recuperat el 29, febrer, 2020, de https://journals.openedition.org/teoros/3367

Beni, M. C. (2001). Análise Estrutural do Turismo. São Paulo: Editora SENAC.

Beni, M. C. (2020). Saturação e rejeição ao turismo nas destinações turísticas. Revista Brasileira de Pesquisa em Turismo, 14(2).

Butler, R. W. (1980). The concept of a tourist area cycle of evolution: Implications for management of resources. Canadian Geographer, 24(1), 5-12.

Campos, E. C. (2008). De São Paulo a Barcelona (e outros itinerários): gentrificação e revitalização nas cidades. Revista Percursos, Florianópolis, 9(2), 100-102.

Colau, A. (2014). Mass tourism can kill a city - just ask Barcelona's residents. The Guardian. Retrieved on 10, abril, 2020, from

https://www.theguardian.com/commentisfree/2014/sep/02/mass-tourism-kill-city-bar celona

Colau, A. (2020). Europe's cities are leading the fight against xenophobia and the climate crisis. The Guardian. Retrieved on 09, abril, 2020, from https://www.theguardian.com/world/commentisfree/2020/mar/06/europe-cities- democracymunicipal-movement-grassroots-climate-crisis-xenophobia

Colomb, J., \& Novy, J. (2016). Protest and Resistance in the Tourist City. Retrieved on 29, fevereiro, 2020, from 
https://www.researchgate.net/publication/332718780_Protest_and_Resistance_in_th e_Tourist_City

Chibás, E. (2014). Bye bye Barcelona [Vídeo]. Retrieved on 01, março, 2020, from https://www.youtube.com/watch?v=kdXcFChRpmI.

Delgado, M. (2008). Turismofobia. El País. Recuperado em 23, fevereiro, 2020, de https://elpais.com/diario/2008/07/12/catalunya/1215824840_850215.html

Donaire, J. A. (2008). L'efervescència de la 'turismofòbia. Barcelona Metrópoles - Revista d'informació i pensament urbans, Peru, (72). Recuperat el 23, febrer, 2020, de http://www.publicacions.bcn.es/b_mm/bmm72/bmm72.pdf.

Doxey, J. (1975). Development of tourism destinations. Torbay, Inglaterra.

Ferraz, V. S. (2013). Hospitalidade Urbana em Grandes Cidades. São Paulo em foco. Tese de Doutorado. Faculdade de Arquitetura e Urbanismo, Universidade de São Paulo, USP, São Paulo, SP, Brasil. Recuperado de https://www.teses.usp.br/teses/disponiveis/16/16139/tde10072013-161802/publico/TESE_VALERIA_FERRAZ.

Fundación del Español Urgente - Fundéu. (2017). turismofobia, neologismo válido. Recuperado de https://www.fundeu.es/recomendacion/turismofobia-neologismo-valido/

García, S., Barrera, D., \& Scalici, M. (2019). Touristification in historic cities: Reflections on Malaga. Revista de Turismo Contemporâneo, Natal, 1(7), 93-115.

González, A. (2018). Venice: the problema of overtourism and the impact of cruises. Investigaciones Regionales. Retrieved on 23, fevereiro, 2020, from https://investigacionesregionales.org/article/venice-the-problem-of-overtourism-andtheimpact-of-cruises/.

Hall, C. M. (2019). Constructing sustainable tourism development: The 2030 agenda and the managerial ecology of sustainable tourism. Journal of Sustainable Tourism, 17(1).

Huete, R., \& Mantecón, A. (2018). El auge de la turismofobia ¿hipótesis de investigación o ruido ideológico. Revista de Turismo y Patrimonio Cultural, Alicante, Espanha, 16(1), 9-19.

Krippendorf, J. (2002). Sociologia do turismo: para uma nova compreensão do lazer e das viagens. (3a. ed.). São Paulo: Aleph.

Lefebvre, H. (1974). Le droit à la ville. L Homme et la société, 6, 29-35.

Mansilla, J. A. (2018). Vecinos em peligro de extinción. Turismo urbano, movimientos sociales y exclusión socioespacial en Barcelona. Revista de Turismo y Patrimonio Cultural, Lima, Peru, 16(2), 279-286.

Marconi, M. A., \& Lakatos, E. M. (2002). Técnicas de Pesquisa. (5a. ed.). São Paulo: Atlas.

Milano, C. (2018). Overtourism, malestar social y turismofobia: um debate controvertido. Revista de Turismo y Patrimonio Cultural, Lima, Peru, 16(3).

Milano, C., Novelli, M., \& Cheer, J., M. (2019). Overtourism and tourismphobia: a journey through four decades of tourism development, planning and local concerns. Tourism Planning and Development, 16(4), 353-357. 
Observatori del turisme a Barcelona: ciutat i regió. (2019). Recuperat el 10, abril, 2020, de https://ajuntament.barcelona.cat/turisme/sites/default/files/capsula_1_iaot b19_0.pdf

Oliveira, A. (2017). Atentados em barcelona e cambrils: as últimas notícias dos ataques terroristas na espanha. El país internacional. Recuperado em 20, outubro, 2019, de https://brasil.elpais.com/brasil/2017/08/17/internacional/1502987924_138296.html

O'Reilly, A. M. (1986). Tourism carrying capacity:concept and issues. Tourism Management, 7(4), 254-258.

Perkumiené, D., \& Pranskuniené, R. (2019). Overtourism: between the right to travel and residents' rights. Sustainability Magazine, Kaunas, Lituânia, 11.

Postma, A., \& Schmuecker, D. (2017). Understanding and overcoming negative impacts of tourism in city destinations: conceptual model and strategic framework. Journal of Tourism Futures, 3(2), 144-156.

Quaglieri D., A. Q. (2018). Turismofobia, ou o turismo como fetiche. Revista do Centro de Pesquisa e Formação, São Paulo, 22-30.

Ribeiro, D. A. (2014). Reflexões sobre o conceito e a ocorrência do processo de gentrification no Parque Histórico do Pelourinho, Salvador - BA. Cad. Metropole, São Paulo, 16(32), 461486.

Swarbrooke, J. (2000). Turismo sustentável: setor público e cenários geográficos. São Paulo: Aleph.

Triviños, A. N. S. (2008). Introdução à pesquisa em ciências sociais: a pesquisa qualitativa em educação. São Paulo: Atlas.

Vives-Miró, S., \& Rullan, O. (2017). ¿Desposesión de vivienda por turistización?:

Revalorización y desplazamientos en el Centro Histórico de Palma (Mallorca). Revista de Geografía Norte Grande, Santiago, Chile, 6, 753-71.

\section{FORMATO PARA CITAÇÃO DESTE ARTIGO}

OLIVEIRA, J. L. S., NEVES, C. C. S., PANOSSO NETTO, A., \& SEVERINI, V. F. (2021). Turismofobia em Barcelona: um tema (que era?) emergente. Revista de Turismo Contemporâneo, 9(3), 325-342. https://doi.org/10.21680/2357-8211.2021v9n3ID23619 